\title{
PRESSURE COEFFICIENTS ACTING UPON THE CYLINDER OBTAINED BY NUMERICAL AND EXPERIMENTAL ANALYSIS
}

Soňa MEDVECKÁ ${ }^{1, *}$, Ol'ga IVÁNKOVÁ ${ }^{1}$, Marek MACÁK $^{2}$

1 Department of Structural Mechanics, Faculty of Civil Engineering, Slovak University of Technology in Bratislava, Radlinského 11, 81005 Bratislava, Slovakia.

2 Department of Mathematics and Descriptive Geometry, Faculty of Civil Engineering, Slovak University of Technology in Bratislava, Radlinského 11, 81005 Bratislava, Slovakia. corresponding author: sona.medvecka@stuba.sk.

\section{Abstract}

Analysis of wind flow acting upon high-rise buildings is a very common topic. This paper deals with experiment in the Boundary Layer Wind Tunnel (BWLT) in Bratislava and comparison with the computational fluid dynamics (CFD) simulation and values given in the Eurocode. The analyzed object was the model of building with circular cross section (cylinder). External wind pressure coefficients were compared in three height levels of model.

\section{Keywords:}

Wind flow;

External wind pressure coefficients;

Experimental measurements; ANSYS;

CFD.

\section{Introduction}

Analyzing the wind effects and determining the external pressure coefficient $c_{p e}$ is one of the major problems for structural engineers nowadays. It plays an important role in structural design [1]. Value of $c_{p e}$ is given in Eurocode only for rectangular and circle plan buildings. Experimental measurements in wind tunnel and wind flow simulation are used to determine $c_{p e}$ for other building shapes [2]. Aim of this article is a comparison of values of external pressure coefficient $c_{p e}$ from experimental measurements in BWLT and from Eurocode and CFD simulation. We have performed this comparison at three height levels of model, i.e. at the upper edge (A), in the middle (B), and at the lower edge (C).

\section{Calculation of external pressure and coefficient $c_{p e}$ according to EN 1991-1-4}

A cylinder-shaped building was analyzed. This shape was chosen because it is described also in the Eurocode 1991-1-4. The calculation of external pressure $c_{p e}$ on a building of a cylindrical shape [3]:

$c_{p e}=c_{p 0} \cdot \psi_{\lambda \alpha}$,

where $c_{p 0}$ is the external pressure coefficient without free-end flow and $\psi_{\lambda a}$ (Eq.2) is the end-effect factor:

$$
\psi_{\lambda \alpha}=\psi_{\alpha}+\left(1-\psi_{\lambda}\right) \cdot \cos \left\{\frac{\pi}{2} \cdot\left(\frac{\alpha-\alpha_{\text {min }}}{\alpha_{A}-\alpha_{\text {min }}}\right)\right\} .
$$

The value of $c_{p 0}$ is given in Fig. 1 as a function of angle $\alpha$, where for analysed model the Reynolds number $1 \times 10^{7}$ was calculated. The resulting values and direction of external pressure coefficients $c_{p e}$ for analysed circular cylinders are shown in Fig. 2. 

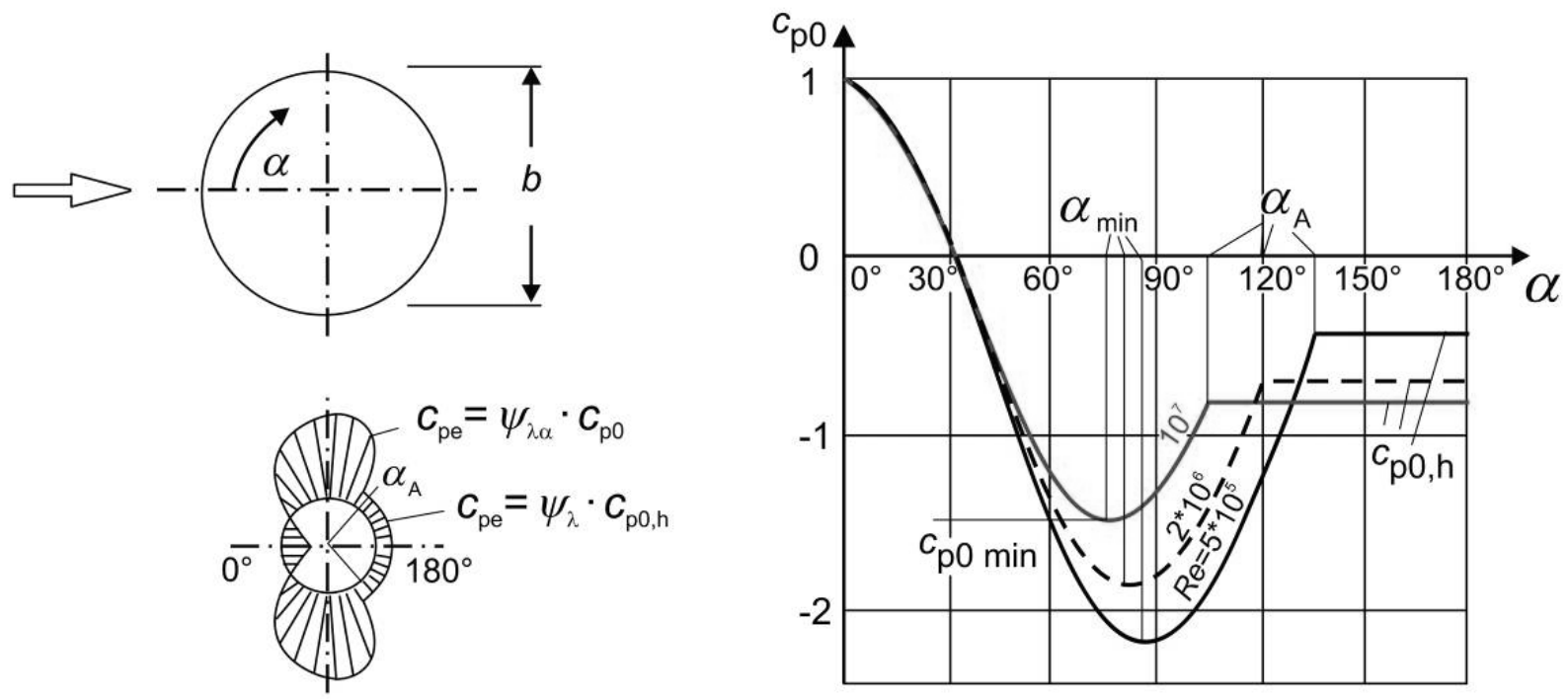

Fig. 1: Pressure distribution for cylinder and for different Reynolds number ranges and without endeffects, EN 1991-1-4.

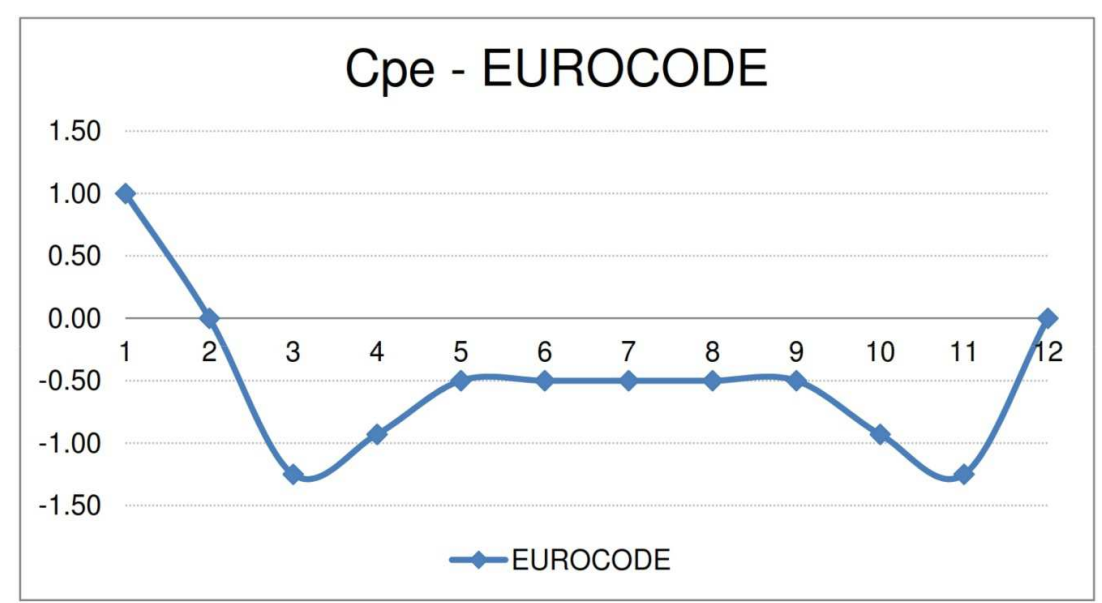

Fig. 2: Value of external pressure coefficients $c_{p e}$ for analysed cylinder according to the Eurocode.

\section{Determination of external pressure $c_{p e}$ by experiment in BLWT wind tunnel}

The experimental research was carried out at the STU in Bratislava, in the Boundary Layer Wind Tunnel (BLWT). In the BLWT STU Tunnel (Fig. 3) there are two operating areas. In the front working area, a uniform wind flow with small deviations from the average wind speed has been generated. It is appropriate for examining massive models and for determining the ultimate distribution of pressures on investigated objects. In the rear working area, the turbulent wind flow is generated by the boundary layer located before the rear working area. This stream of wind simulates the real rough terrain. The scale of model ranges from $1: 360$ to $1: 380$. It meets all requisite model specifications. The smallest Reynolds number value is equal to $1 \times 10^{4}$ to ensure similarity with the real airflow around the structure [2, 4]. 

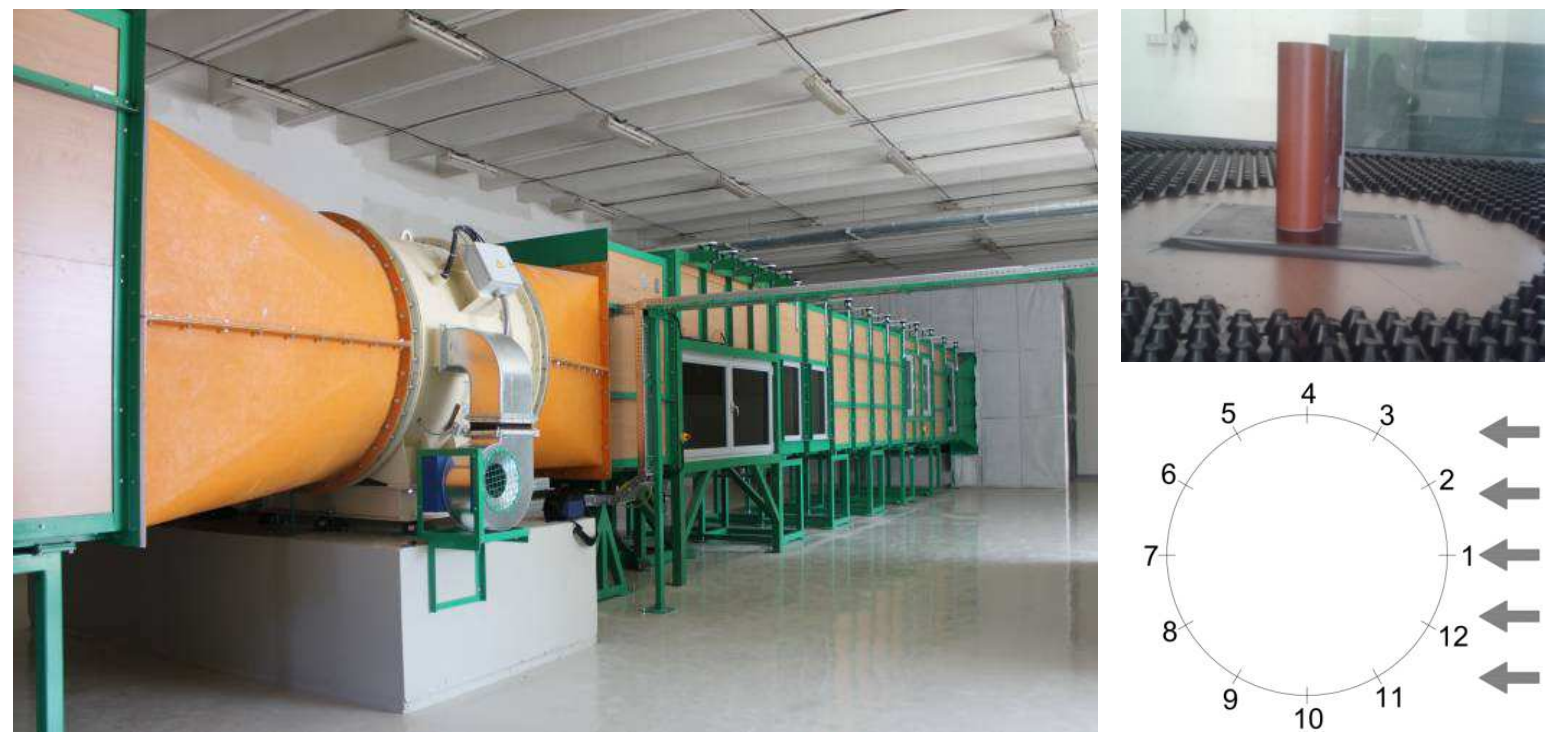

Fig. 3: BLWT STU wind tunnel and model.

The shape of model is a cylinder of height 0.30 meters and its diameter is 0.11 meters. 12 sensors were placed at each height level, Fig. 3 . The value of pressure $p(z)$ acting on model was determined by experimental measurement made in the rear operating space (ROS). From this pressure, we have calculated the exposure factor $c_{p e}$ according to (3), while we have obtained basic velocity pressure $q_{b}$ on the basis of air density $\rho$ and reference wind velocity $v_{\text {ref }}$ in tunnel [4]:

$$
c_{p e}=\frac{p(z)}{q_{b}}=\frac{p(z)}{1 / 2 \cdot \rho \cdot v^{2} r e f}
$$

where: $v_{r e f}=11.53 \mathrm{~m} / \mathrm{s}, \rho=1.15 \mathrm{~kg} / \mathrm{m}^{3}$.

We have applied this procedure at three levels of model, i.e. at the upper edge $(A)$, in the middle (B), and at the lower edge (C), Fig. 3. The values of $c_{p e}$ from experimental measurements are presented in Fig. 4.

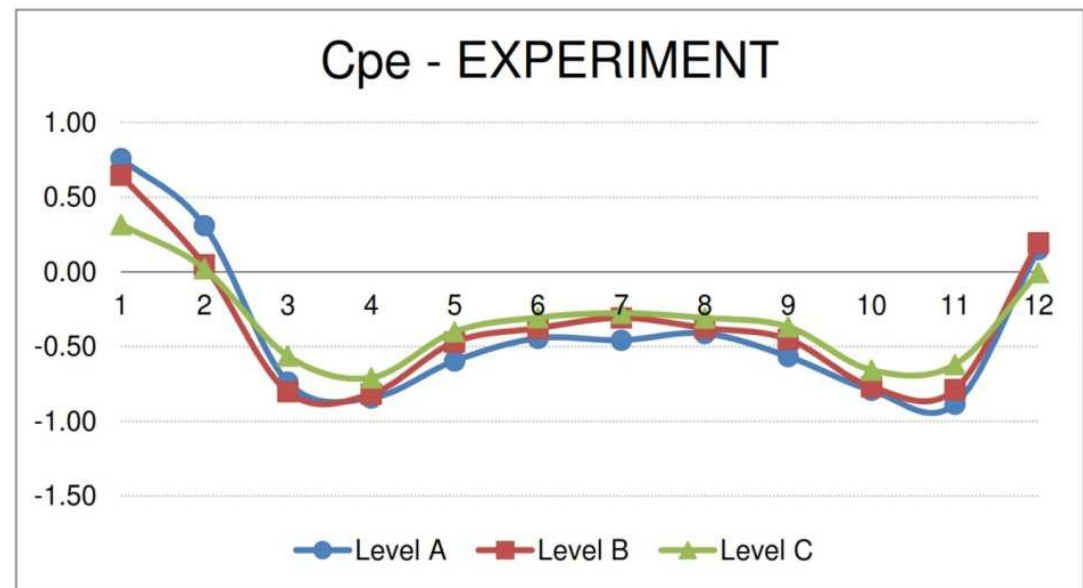

Fig. 4: Values of $c_{p e}$ for model from experimental measurements (Level A, B, and C).

\section{Determination of external pressure $c_{p e}$ by computational fluid dynamics simulation}

For CFD simulation we choose ANSYS 18.1 [5]. Size of the computational domain for coarse grid was $6 \times 4 \times 1.8 \mathrm{~m}^{3}(l \times w \times h)$ according to recommended maximum value of block ratio $3 \%$ [6]. The distance from the object to the inlet, sides and top of the domain is at least five times the height of the object, and the distance from the outlet is at least eleven times the height, according to the 
guidelines by [6,7]. Mesh was generated using the Adaptive Size Function. Element size on surface of the object was $0.005 \mathrm{~m}$ and inflatation was applied on the object with 5 layers with growth rate of $20 \%$ [8]. Generated were 108924 elements with 40489 nodes. In fluent was mesh transferred to polyhedral mesh with 48176 cells and 130569 nodes.

In general as inlet boundary condition logarithmic wind speed profile was used defined as:

$u(z)=\frac{u^{*}}{\kappa} \ln \frac{z+z_{0}}{z_{0}}$,

where $u(z)$ is mean wind velocity, $u^{*}$ is shear velocity, $z$ is elevation, $z_{0}$ is aerodynamic roughness height, $\kappa$ is von Karman constant [9]. Inputs for $k-\varepsilon$ model require also turbulent kinetic energy $k$ and turbulence dissipation rate $\varepsilon$ as follows:

$k=\frac{u^{* 2}}{\sqrt{C_{\mu}}}$,
$\varepsilon(z)=\frac{u^{* 3}}{\kappa\left(z+z_{0}\right)}$,

where $C_{\mu}$ constant in $k-\varepsilon$ model.

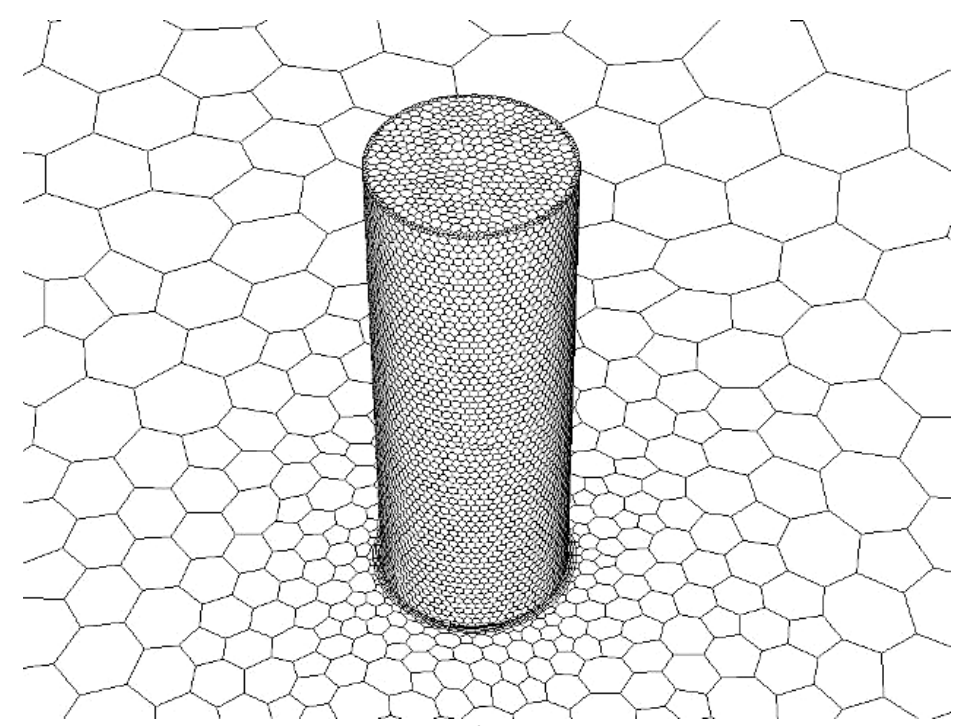

Fig. 5: Detailed view of the computational grid.

The CFD simulations were performed using the commercial CFD code ANSYS Fluent 18.1 [5]. All computations were performed as pressure-based, transient, without production limiter. From solution methods was used SIMPLE pressure-velocity coupling scheme with second order spatial discretization, for transient formulation was used second order implicit method. Solution was initialized with hybrid initialization with default setting. Time step size was set 0.0025 and number of time steps 200. The values of $c_{p e}$ from CFD simulation are in Figs. 6 and 7. 


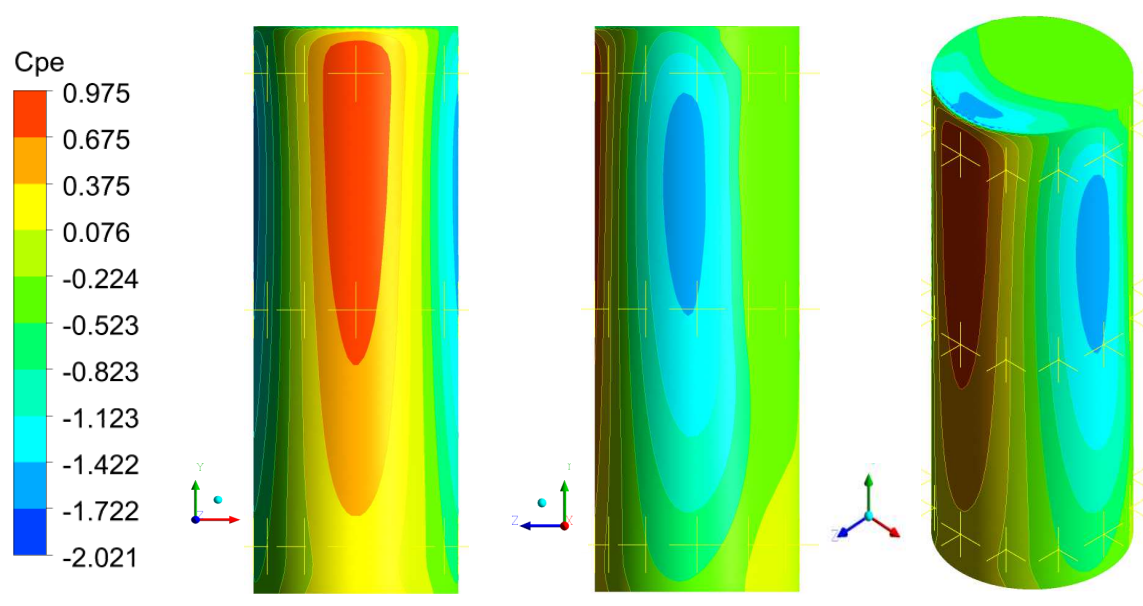

Fig. 6: Values of $c_{p e}$ for models from CFD simulation (front view, rear view, and axonometry).

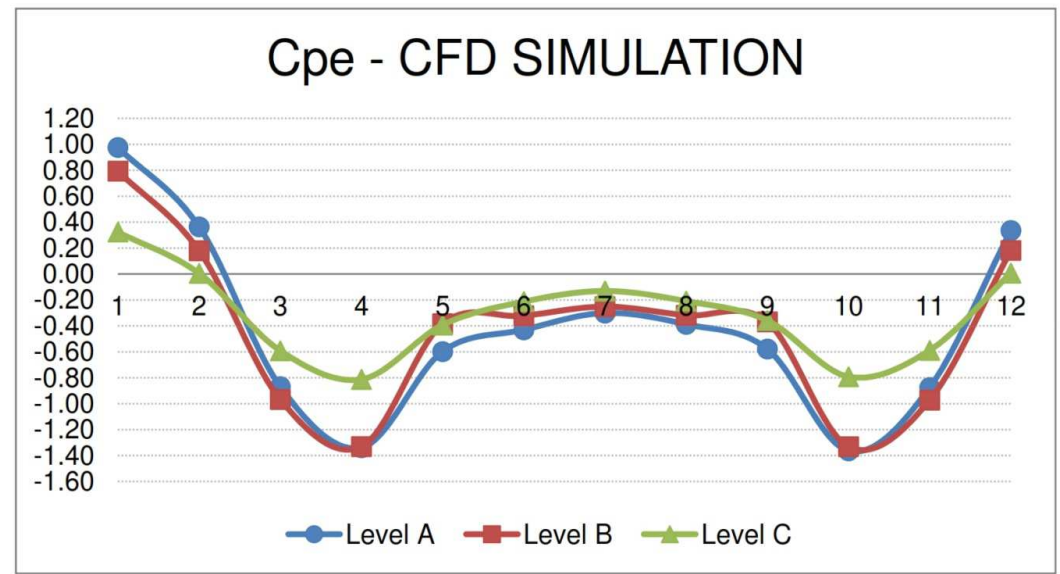

Fig. 7: Values of $c_{p e}$ for model from CFD simulation (Level A, B, and C).

\section{Conclusion}

Comparison of the values of external pressure coefficient obtained by three methods is presented in Figs. 8, 9, and 10 (Level A, B, and C). Values obtained by numerical analysis and experimental measurements are quite similar. Maximal and minimal values are not changed markedly. Smaller differences were only in the area of induction (sensors No. 4 and 10) from CFD simulation. In other cases, values from experiment and CFD simulation were smaller than a value in the Eurocode. It can be stated that the values measured in the wind tunnel experiment proved to be correct. It is a good assumption for future research.

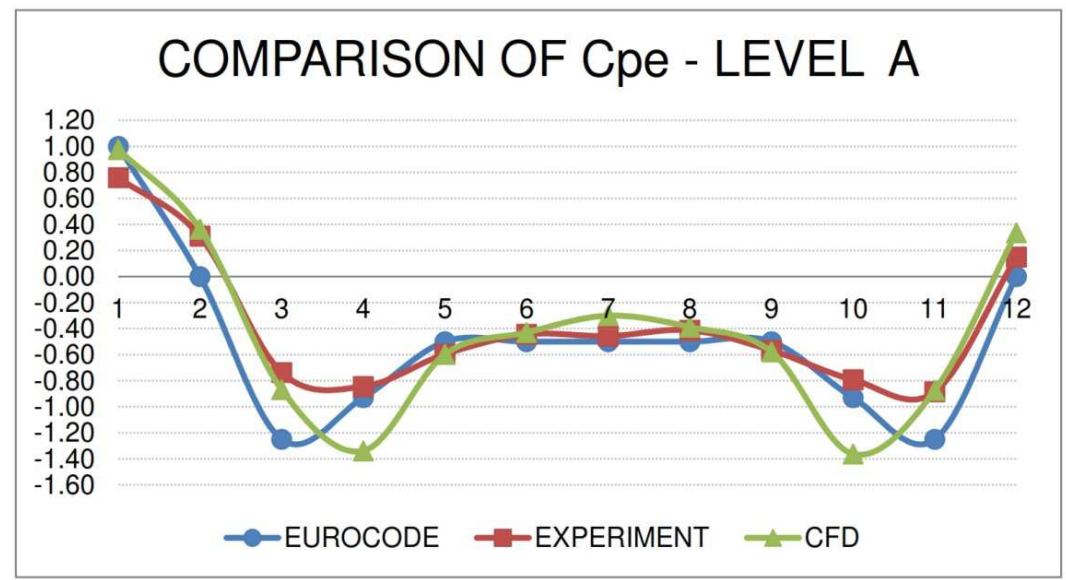

Fig. 8: Comparison of $c_{p e}$ for model for level A. 


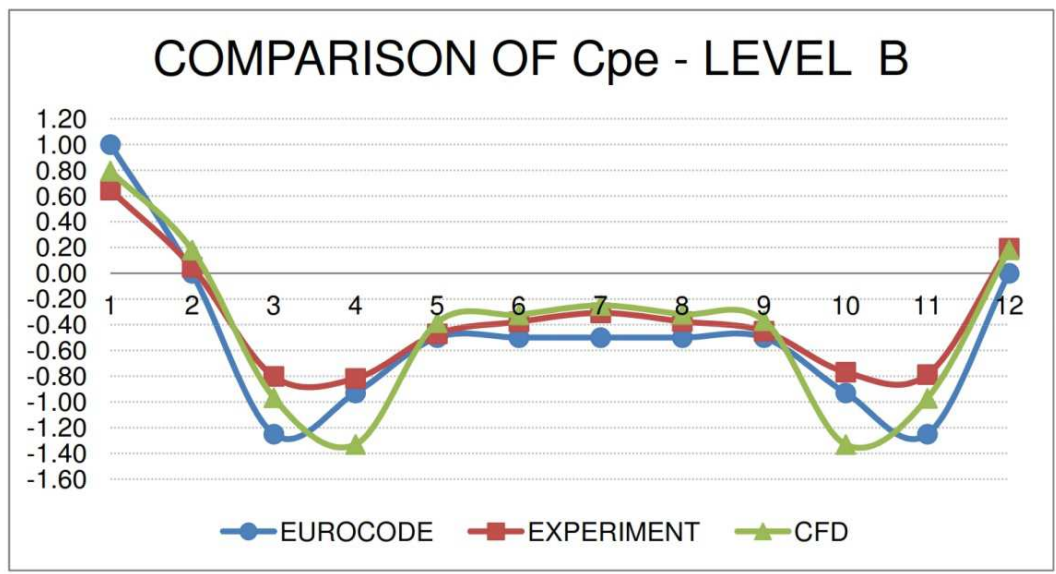

Fig. 9: Comparison of $c_{p e}$ for model for level B.

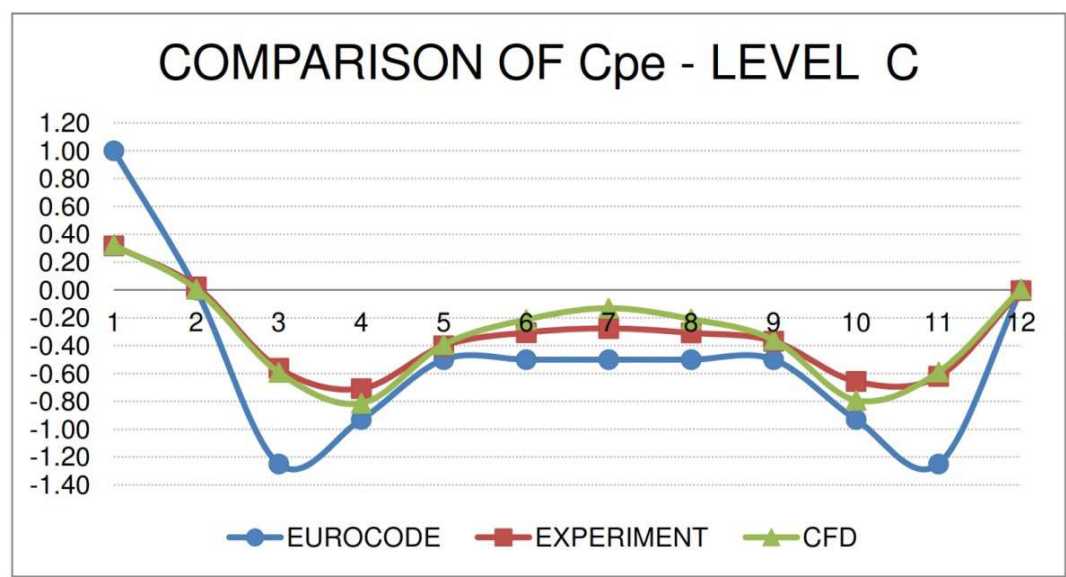

Fig. 10: Comparison of $c_{p e}$ for model for level C.

To summarize graphically the values of $c_{p e}$ obtained by three different methods, the results from Figs. 2, 4, 7, and 8 - 10 have been included into a single graph, see Fig. 11.

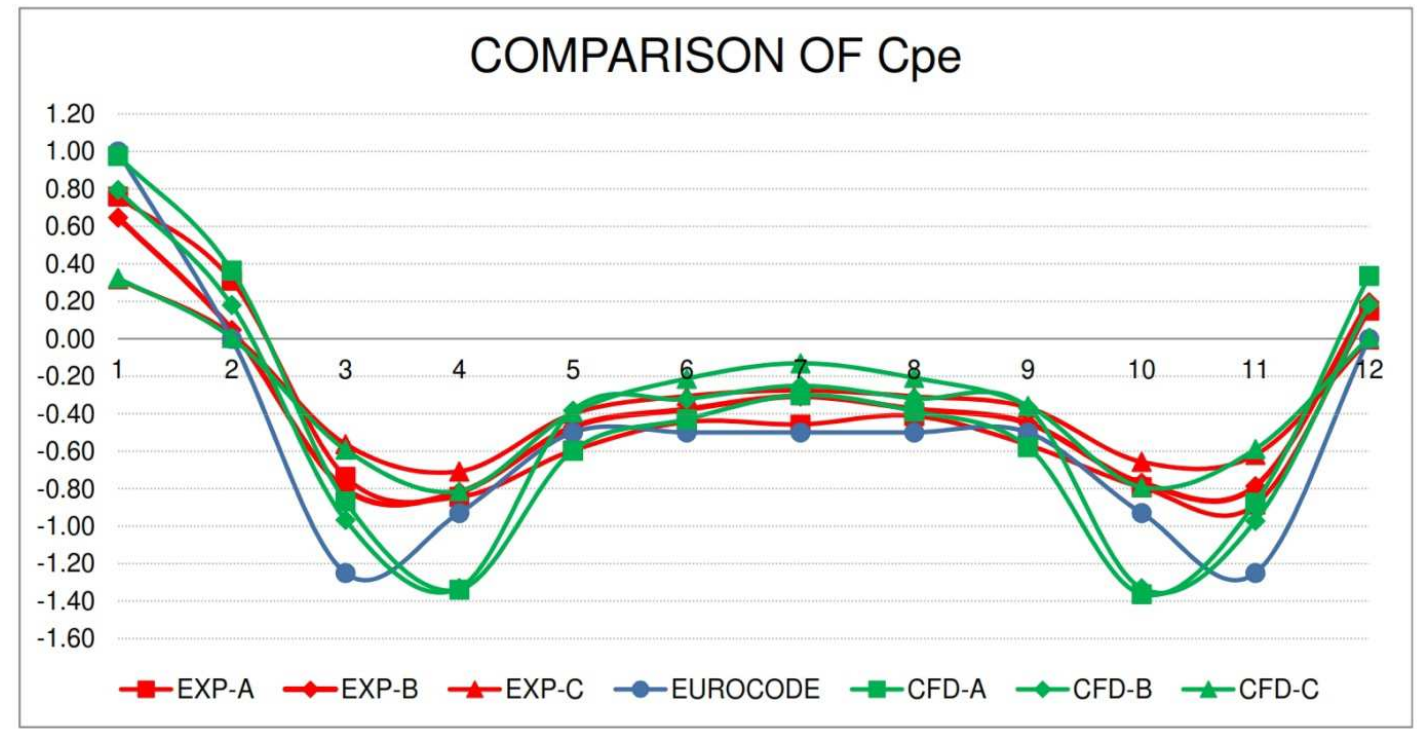

Fig. 11: Comparison of $c_{p e}$ for model (Level A, B, and C). 


\section{Acknowledgement}

This paper was written with support of the Slovak Grant Agency VEGA. Registration numbers of the projects are 1/0544/15, 1/0608/15, and APVV-15-0522.

\section{References}

[1] KOTRASOVÁ, K. - HEGEDÜŠOVÁ, I. - HARABINOVÁ, S. - PANULINOVÁ, E. KORMANÍKOVÁ, E.: The possible causes of damage to concrete tanks, numerical experiment of fluid-structure-soil interaction (Book Chapter). Key Engineering Materials, Vol. 738, 2017, pp. 227-237.

[2] POROWSKÁ, A. - KŁAPUT, R. - FLAGA, A.: Wind tunnel tests of tent halls of different construction. Dynamics of Civil Engineering and Transport Structures and Wind Engineering DYN-WIND'2017, Matec Web of Conferences, Vol. 107, 2017.

[3] EN 1991-1-4 Eurocode 1: Actions on structures. Part 1-4: General action, 2005.

[4] HUBOVÁ, O. - KONEČNÁ, L.: The Influence of the Wind Flow around the Free Ends of High-Rise Building on the Values of External Wind Pressure Coefficients. Applied Mechanics and Materials, Vol. 837, 2016, pp. 203-208.

[5] ANSYS Inc.: ANSYS Fluent User's Guide, Release 18.1.2017.

[6] TOMINAGA, Y. - MOCHIDA, A. - YOSHIE, R. - KATAOKA, H. - NOZU, T. - YOSHIKAWA, M. SHIRASAWA, T.: AlJ guidelines for practical applications of CFD to pedestrian wind environment around buildings. J Wind Eng Ind Aerod, Vol. 96, Iss.10-11, 2008, pp. 1749-1761.

[7] MICHALCOVÁ, V. - LAUSOVÁ, L. - KOLOS, I.: Numerical modelling of flow around thermally loaded object. Dynamics of Civil Engineering and Transport Structures and Wind Engineering DYN-WIND'2017, Matec Web of Conferences, Vol. 107, 2017.

[8] CHUNG, T.J.: Computational fluid dynamics. $2^{\text {nd }}$ edition, Cambridge University Press, New York, 2010, $1034 \mathrm{p}$.

[9] WILCOX, D.C.: Turbulence modelling for CFD. $3^{\text {rd }}$ edtion, La Canada CA: DCW industries, 2006, $522 \mathrm{p}$. 